\title{
Correction to: Comparative Study of the Dose-Dependence of OATPIB Inhibition by Rifampicin Using Probe Drugs and Endogenous Substrates in Healthy Volunteers
}

\author{
Issey Takehara ${ }^{1,2}$ - Takashi Yoshikado ${ }^{3,4} \cdot$ Keiko Ishigame ${ }^{4}$ • Daiki Mori ${ }^{2} \cdot$ Ken-ichi Furihata $^{5} \cdot$ Nobuaki Watanabe $^{6} \cdot$ Osamu Ando $^{6}$. \\ Kazuya Maeda ${ }^{2} \cdot$ Hiroyuki Kusuhara ${ }^{4} \cdot$ Yuichi Sugiyama $^{2}$
}

Published online: 21 February 2019

(C) Springer Science+Business Media, LLC, part of Springer Nature 2019

\section{Correction to: Pharm Res (2018) 35: 138 \\ https://doi.org/I 0.1007/s I 1095-0 I 8-24 I6-3}

There was a miscalculation of coproporphyrin I $\mathrm{AUC}_{0-24 \mathrm{~h}}$ in the published article (Volume 35, Number 7). After the correction of $\mathrm{AUC}_{0-24 \mathrm{~h}}$, $\mathrm{AUC}$ ratio and $\mathrm{R}$-square were recalculated. Then, following corrections were made in the abstract, the body, Fig. 3, Fig. 4 and Table 2 in this article. The interpretation of data in this article was not influenced.

The corrected sentences are below.

Page 1.

\section{Abstract}

line 20: coproporphyrin $\mathrm{I}\left(\mathrm{r}^{2}=0.78\right)$.

line 23: $\left(r^{2}=0.48-0.70\right)$.

Issey Takehara and Takashi Yoshikado contributed equally to this work.

The online version of the original article can be found at https://doi.org/l0. |007/s | |095-0 | 8-24|6-3

Hiroyuki Kusuhara

kusuhara@mol.f.u-tokyo.ac.jp

Biomarker Department, Daiichi Sankyo Co. Ltd., Tokyo, Japan

2 Laboratory of Molecular Pharmacokinetics, Graduate School of Pharmaceutical Sciences, The University of Tokyo, 7-3-I, Hongo, Bunkyo-ku, Tokyo I I3-0033, Japan

3 Present address: Laboratory of Clinical Pharmacology, Yokohama University of Pharmacy, 60I Matano-cho, Totsuka-ku, Yokohama-shi, Kanagawa 245-0066, Japan

4 Sugiyama Laboratory, RIKEN Innovation Center, RIKEN, Yokohama, Japan

5 P-One Clinic, Keikokai Medical Corp, Tokyo, Japan

6 Drug Metabolism \& Pharmacokinetics Research Laboratories, Daiichi Sankyo Co., Ltd., Tokyo, Japan
Page 5.

Effect of Rifampicin on the Plasma Concentrations of Coproporphyrin I.

line 4: 2.3- and 3.5-times higher.

Correlations between the $\mathrm{AUC}_{\mathbf{0 - 2 4 h}}$ of Endogenous OATPIB Substrates, and of these with the $A U C_{0-24 h}$ of Atorvastatin.

line 6: coproporphyrin $\mathrm{I}\left(\mathrm{r}^{2}=0.78\right)$.

line 8: atorvastatin ( $\mathrm{r}^{2}$ of $0.65,0.70$ and 0.48 , respectively). 
The corrected Figures and Table appears below.

Page 9.

Fig. 3e

\section{E coproporphyrin I}

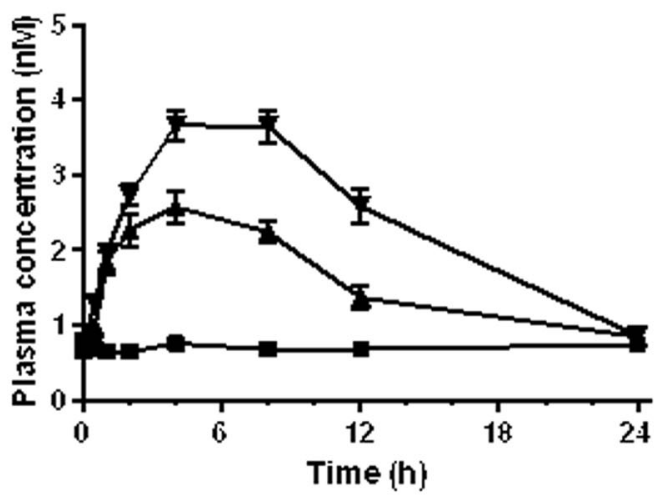

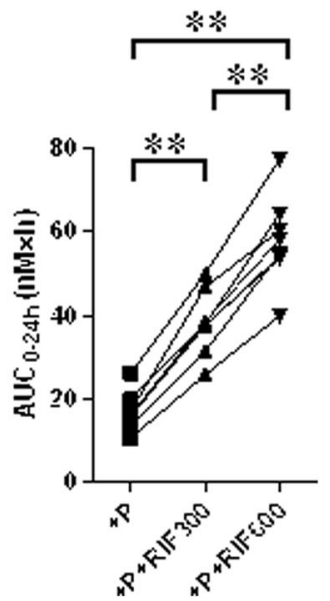

Page 10

Table 2, line 6 Coproporphyrin I.

\begin{tabular}{|c|c|c|c|c|c|c|}
\hline $\begin{array}{l}\text { Probe drug } \\
\text { Coproporphyrin I }\end{array}$ & $\begin{array}{l}\text { Control } \\
\text { nd }\end{array}$ & $\begin{array}{l}+P \\
16.8 \pm 1.6\end{array}$ & $\begin{array}{l}+\mathrm{RIF} 300 \\
38.1 \pm 2.7^{*} *\end{array}$ & $\begin{array}{l}\text { Fold change }^{a} \\
2.3 \pm 0.1\end{array}$ & $\begin{array}{l}+\mathrm{RIF} 600 \\
57.8 \pm 3.8 * *,+十\end{array}$ & $\begin{array}{l}\text { Fold change }{ }^{a} \\
3.5 \pm 0.1\end{array}$ \\
\hline
\end{tabular}
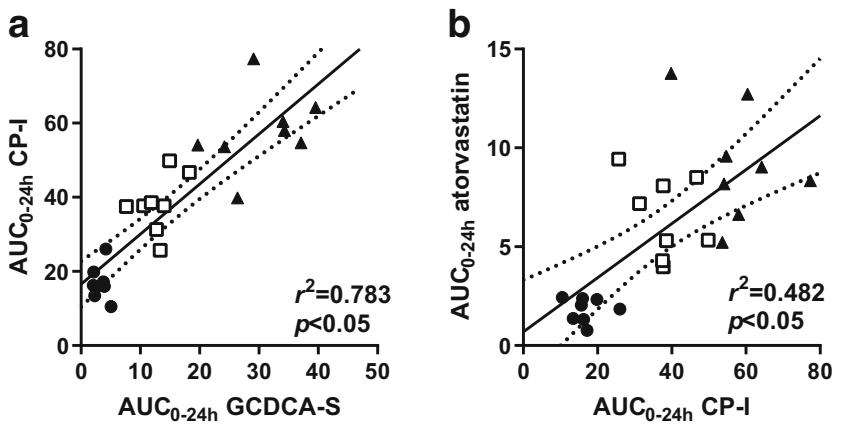

Fig. 4 a Correlation between $\mathrm{AUC}_{0-24 \mathrm{~h}}$ of GCDCA-S and CP-I. b Correlation between $\mathrm{AUC}_{0-24 \mathrm{~h}}$ of CP-I and atorvastatin

Publisher's Note Springer Nature remains neutral with regard to jurisdic-

tional claims in published maps and institutional affliations. 